\title{
THE EFFECT OF FUEL DOSE DIVISION ON THE EMISSION OF TOXIC COMPONENTS IN THE CAR DIESEL ENGINE EXHAUST GAS
}

\author{
Dariusz Pietras, $\mathrm{PhD}$ \\ University of Bielsko-Biala, Poland
}

\begin{abstract}
The article discusses the effect of fuel dose division in the Diesel engine on smoke opacity and composition of the emitted exhaust gas. The research activities reported in the article include experimental examination of a small Diesel engine with Common Rail type supply system. The tests were performed on the engine test bed equipped with an automatic data acquisition system which recorded all basic operating and control parameters of the engine, and smoke opacity and composition of the exhaust gas. The parameters measured during the engine tests also included the indicated pressure and the acoustic pressure. The tests were performed following the pre-established procedure in which 9 engine operation points were defined for three rotational speeds: 1500, 2500 and $3500 \mathrm{rpm}$, and three load levels: 25, 40 and $75 \mathrm{Nm}$. At each point, the measurements were performed for 7 different forms of fuel dose injection, which were: the undivided dose, the dose divided into two or three parts, and three different injection advance angles for the undivided dose and that divided into two parts. The discussion of the obtained results includes graphical presentation of contests of hydrocarbons, carbon oxide, and nitrogen oxides in the exhaust gas, and its smoke opacity. The presented analyses referred to two selected cases, out of nine examined engine operation points. In these cases the fuel dose was divided into three parts and injected at the factory set control parameters. The examination has revealed a significant effect of fuel dose division on the engine efficiency, and on the smoke opacity and composition of the exhaust gas, in particular the content of nitrogen oxides. Within the range of low loads and rotational speeds, dividing the fuel dose into three parts clearly improves the overall engine efficiency and significantly decreases the concentration of nitrogen oxides in the exhaust gas. Moreover, it slightly decreases the contents of hydrocarbons and carbon oxide. In the experiment the contents of nitrogen oxides markedly increased with the increasing injection advance angle for the undivided dose and that divided into two parts. This, in turn, led to the decrease of the contents of hydrocarbons and carbon oxide. Fuel dose division into two and three parts leads to the increase of smoke opacity of the exhaust gas, compared to the undivided dose.
\end{abstract}

Keywords: exhaust opacity, exhaust emissions, Diesel engine, Common Rail, fuel dose division

\section{INTRODUCTION}

A concept of multi-part fuel dose division into three or five separate parts, Multijet system for instance, see Fig.1, has nowadays become a standard solution in contemporary Diesel engine control systems. Engines which make use of the above control strategy include most popular Volvo Penta engines, series D3 to D6, with powers ranging from 100 to $300 \mathrm{~kW}$, and Cummins engines, for instance QSB6.7/QSB7 for Marine, with powers from 184 to $405 \mathrm{~kW}$. These engines, frequently used as basic equipment of contemporary tourist boats, are equipped with high-pressure Common Rail systems and piezoelectric injectors.

Particular injected fuel doses bear the names of: pilot-, pre-, main-, after- and post-injection. The pilot injection, which precedes the main injection by about 0,7 milliseconds, provides time needed for proper fuel mixing with air. The pre-injection decreases the delay time of the main injection in order to decrease the emission of nitrogen oxides $\left(\mathrm{NO}_{x}\right)$, noise, and vibration. The after-injection, taking place within milliseconds after the main injection, aims at afterburning all remaining solid particles, while the post-injection supports keeping proper temperature of the exhaust gas to ensure higher 
operating efficiency of the exhaust aftertreatment system. The abovementioned Multijet concept of fuel injection comprises five injection phases, but other systems, which now gain in popularity, divide the fuel dose into 7 or 8 parts $[2,3,4,5,6]$.

The current state of knowledge suggests that the number of injections per one engine work cycle, the amounts of particular fuel dose parts, and the delay or advance angles of the beginning of injection of particular parts, i.e. in general, the overall volume-time characteristics of the fuel injection process significantly affect the heat release and, consequently, the engine performance, as well as the contents of harmful substances in the exhaust gas, including solid particles (mainly soot), and the noise generated by the engine in operation. The results of examination presented in the article and their analyses aim at confirming this thesis.

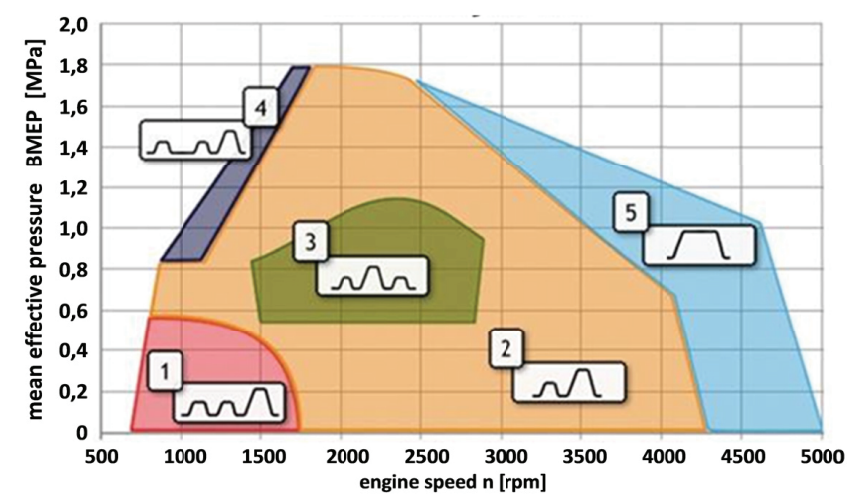

Fig. 1. Sample scheme of Multijet injection system control strategy [1]

\section{METHODOLOGY OF EXAMINATION}

The here reported examination aimed at determining the effect of fuel dose division on the exhaust gas composition and smoke opacity, and on engine operation parameters, in particular those referring to the combustion process itself and the generated noise. These issues were partially analysed in other publications by the author $[7,8]$.

The present examination consisted in measuring basic parameters of engine operation, the chemical composition of the exhaust gas, as well as the indicated and acoustic pressures. The tests were performed in accordance with the pre-established research procedure in which 9 engine operation points were defined for three rotational speeds: 1500, 2500 and 3500 rpm, and three load levels: 25, 40 and $75 \mathrm{Nm}$. Figure 1 shows the torque characteristic of the examined engine with the marked measuring points.

The measuring points were selected in such a way that the measurements were performed for each engine rotational speed and each load level at different modes of fuel dose division and different corrections of the injection advance angle (IAA) from the factory set values. For instance, seven tests were performed at the rotational sped equal to $1500 \mathrm{rpm}$ and the load equal to $25 \mathrm{Nm}$. These tests were done, in the below given order, for the following injection characteristics:

1. 3 dose parts, (pilot-, pre-, and main injection), basic IAA,

2. 2 dose parts, (pre- and main injection), basic IAA,
3. 2 dose parts, IAA correction of the main dose part to $4^{\circ}$ before TDC,

4. 2 dose parts, IAA correction of the main dose part to $8^{\circ}$ before TDC,

5. undivided dose, basic IAA,

6. undivided dose, IAA correction to $4^{\circ}$ before TDC,

7. undivided dose, IAA correction to $8^{\circ}$ before TDC,

A graphical scheme or execution of particular test cases for different fuel injection strategies, discussed above, is given in Fig. 2. The injection advance angle referring to the main injection was constant and the same in tests 1,2 and 5 (marked blue in figures and diagrams). This IAA control resulted from properties of the controller. Having into account that in tests 1 and 2 the fuel dose was divided into three and two parts, respectively, the real angle of fuel injection beginning varied. Switching off, in succession, the pilot and pre-injection phases changed the delay of the fuel injection angle. The IAA correction applied in tests 3 and 6 (marked purple) and tests 4 and 7 (marked yellow) to $4^{\circ}$ and $8^{\circ}$, respectively, before TDC aimed to provide opportunities for measurements at similar real fuel injection values as in test 1 for the dose divided into three parts.

For the rotational speed equal to $1500 \mathrm{rpm}$ the engine load was increased to 50 and $75 \mathrm{Nm}$, and then the measurements were preformed following the above described procedure, which was also applied to the cases of rotational speed equal to $2500 \mathrm{rpm}$ and $3500 \mathrm{rpm}$. At each measuring point the measured parameters were recorded after some time interval, to allow the engine parameters to stabilise.

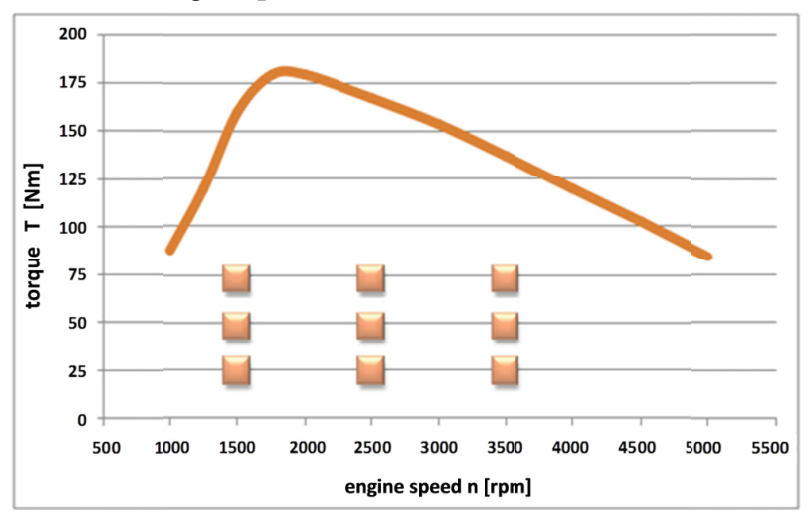

Fig. 2. Torque characteristic of 1.3 Multijet engine with marked measuring points

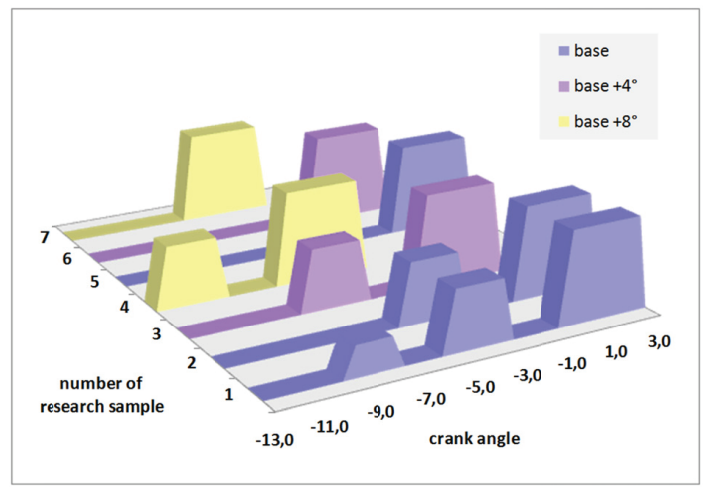

Fig. 3. Graphical presentation of test methodology for different fuel injection strategies 
The measured values were collected in four files. Files 1 and 2 contained data concerning the course of pressure changes in the combustion chamber, which were recorded after each 0,5 ${ }^{\circ} \mathrm{OWK}$ (file 1), and basic data characterising the cycle, such as the indicated pressure and the maximum pressure of the process (file 2). The next file, file 3, contained the data recorded by the code „HAMOWNIA” which monitored the engine test bed operation, while the last file, file 4 , collected the data recorded by the code monitoring the engine operation parameters.

\section{OBJECT OF EXAMINATION AND RESEARCH RIG}

The object of examination was a modern four-cylinder Diesel engine supplied by the Common Rail system. The cylinder head has two camshafts, and four valves in each cylinder. The valve train is driven via a chain system with direct transmission between the camshafts. The engine is charged from a turbocharger with intake air cooling system, and is equipped with an exhaust gas recirculation system.

The tests were performed in the laboratory owned by the Department of Combustion Engines and Vehicles, University of Bielsko-Biala. The engine was installed on the research rig and connected with the eddy-current brake Schenck W130. The engine and the research rig are shown in Fig. 4.

The engine motion was controlled using a laboratory Diesel engine controller (Fig. 5), which provided full control of operating parameters by proper settings and current monitoring. It also enabled to "block" certain parameters during the tests so that a change of one operating parameter did not provoke automatic correction of the remaining parameters, a situation which frequently occurs in factory controllers. The controller was built based on the experience gained in earlier research works $[9,10]$ done in the Division of Combustion Engines, University of Bielsko-Biala.

\section{RESULTS OF EXAMINATION}

The tests performed on the engine test bed in accordance with the research programme presented in Chapter 2 enabled to collect results which will be graphically illustrated in the diagrams and discussed in this Chapter. Due to a large number

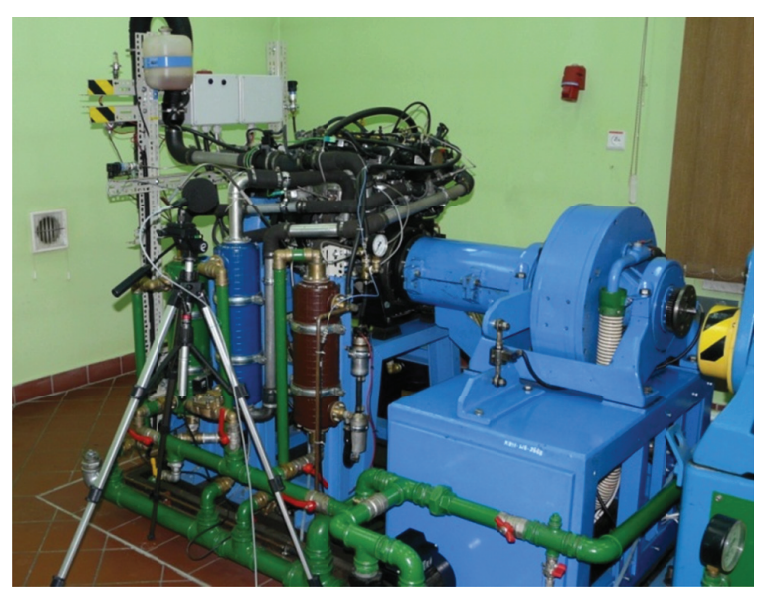

Fig. 4. View of the engine installed on the research rig of performed tests ( 7 tests for each of 9 engine operation points, i.e. 63 tests in total), only the results obtained for two selected engine operation points (14 tests) are presented and discussed. In the selected cases the fuel dose was divided into three parts and injected at the factory set control parameters. For point 1 the rotational speed was equal to $1500 \mathrm{rpm}$ and the load was equal to $25 \mathrm{Nm}$, while for point 2 they were equal to 2500 rpm and $40 \mathrm{Nm}$, respectively. These points can be found in the Multijet injection system control strategy scheme shown in Fig. 1.

Figures $6 \div 10$ show bar graphs of the exhaust gas composition, smoke opacity, and overall engine efficiency as functions of the controlled advance angle of the main injection: with the basic value approximately equal to $1^{\circ}$ before TDC and the accelerated values equal to $4^{\circ}$ and $8^{\circ}$ before TDC, and the dose division characteristic for the selected two engine operation points.

Figure 6 shows the effect of fuel dose division and injection advance angle changes on the contents of nitrogen oxides $\left(\mathrm{NO}_{\mathrm{x}}\right)$ in the exhaust gas. As mentioned in the examination procedure, the value of the injection advance angle refers to the injection of the main dose part, therefore switching off successive dose parts, i.e. the pilot and pre-injection (represented by blue bars) shifts down the beginning of the combustion process, as compared to the division into three parts. Despite a much shorter injection time for the fuel dose divided into two parts and the undivided dose, no increase of the combustion dynamics is observed, which results in keeping the $\mathrm{NO}_{\mathrm{x}}$ contents at a similar level to that characteristic for the dose divided into three parts. For the rotational speed 1500 $\mathrm{rpm}$, a slight increase by $6 \%$ in the $\mathrm{NO}_{\mathrm{x}}$ content is observed, while for $2500 \mathrm{rpm}$ this content decreases by $7 \%$.

Despite a relatively early real beginning of fuel injection, the dose division into three parts confirm mild nature of the heat emission process, which positively affects the contents of nitrogen oxides for the both analysed engine operation points. We can also conclude that for this control mode the overall engine efficiency will be higher than for the dose divided into two parts and undivided.

Increasing the injection advance angle (purple and yellow bars) intensifies the process dynamics, as a result of which the maximum pressure and temperature values also increase. As a further consequence, the $\mathrm{NO}_{\mathrm{x}}$ content in the exhaust gas

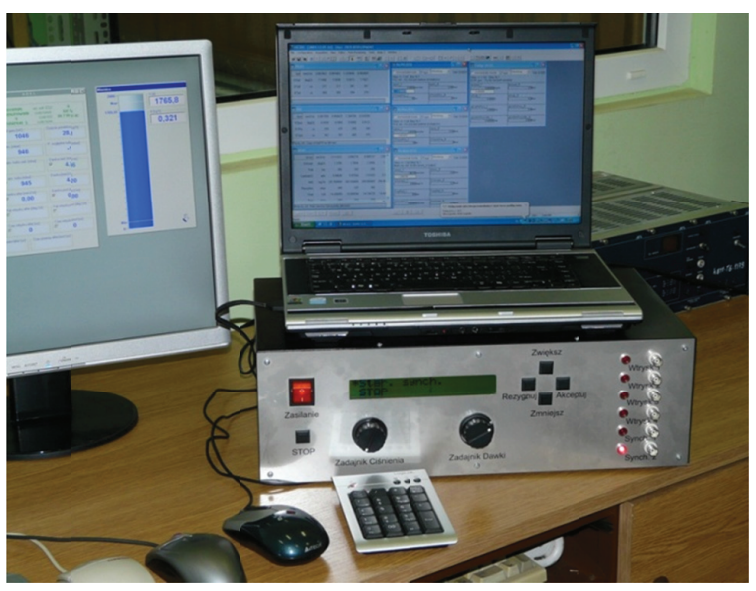

Fig. 5. Laboratory Diesel engine controller 
clearly increases, and the scale of this increase is similar in the both analysed cases. The maximum $\mathrm{NO}_{\mathrm{x}}$ content amounts to $425 \mathrm{ppm}$ for the undivided fuel dose, the TDC equal to $8^{\circ}$ and the rotational speed equal to $1500 \mathrm{rpm}$, and is higher by $97 \%$ by that recorded for the fuel dose divided into three parts.
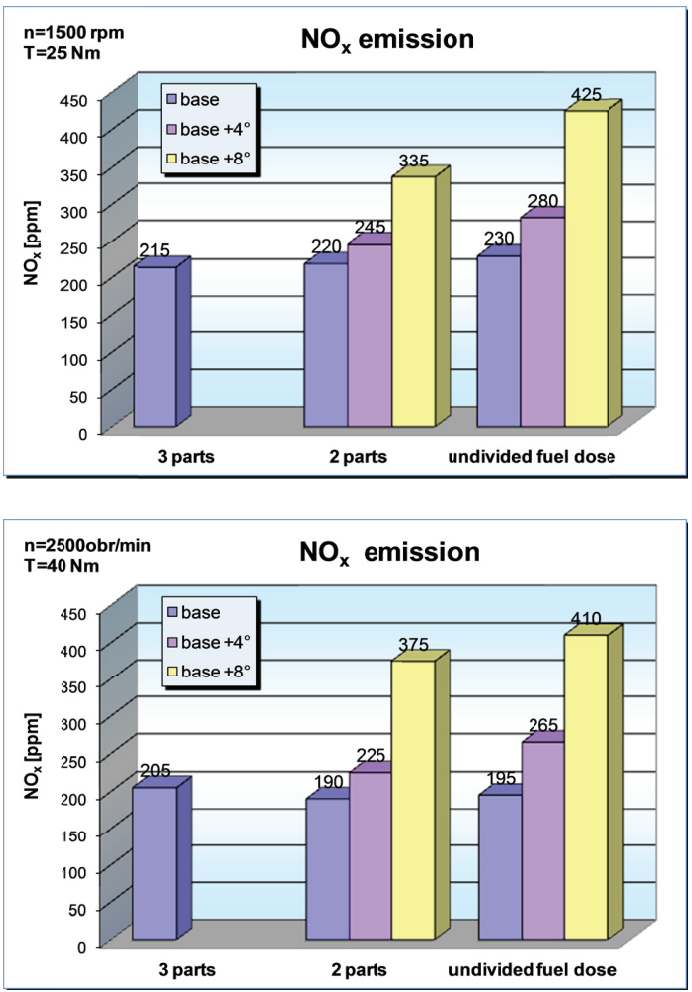

Fig. 6. $N O_{x}$ content in the exhaust gas as function of fuel dose division and injection advance angle changes: $n=1500 \mathrm{rpm}$ and $T=25 \mathrm{Nm}$ (top), and $n=2500 \mathrm{rpm}$ and $\mathrm{T}=40 \mathrm{Nm}$ (down)

The nature of changes of the content of hydrocarbons (HC) in the exhaust gas, which can be observed in Fig. 7, is quite opposite to that observed for $\mathrm{NO}_{x}$. Switching off the pilot and pre injection phases results in significant increase of the $\mathrm{HC}$ content, by $87 \%$ for the rotational speed $1500 \mathrm{rpm}$ and by as much as $102 \%$ for $2500 \mathrm{rpm}$. On the other hand, correcting IAA decreases the HC content. Its values obtained after correction (yellow bars) are at the level approximately higher only by 10 $\div 20 \%$ as compared to the fuel dose divided into three parts.

A similar trend to that recorded for $\mathrm{HC}$ can be observed when analysing the content of carbon oxide (CO) in the exhaust gas. However now, this trend is not as clear and regular as for HC. For the rotational speed $1500 \mathrm{rpm}$ and the fuel dose divided into two parts, no clear trend can be seen and the recorded changes oscillate about the level of $220 \mathrm{ppm}$. For the same rotational speed and the undivided dose, the $\mathrm{CO}$ value for the basic IAA is higher by as much as $200 \%$ (!!!), compared to the dose divided into three parts. Smaller and more regular changes are observed for the rotational speed $2500 \mathrm{rpm}$. Here some analogy to the above discussed $\mathrm{HC}$ content changes can be observed. After correcting IAA to $8^{\circ}$ before TDC, the CO values recorded for the dose divided into two and three parts were similar to each other, or even smaller when the dose was undivided.
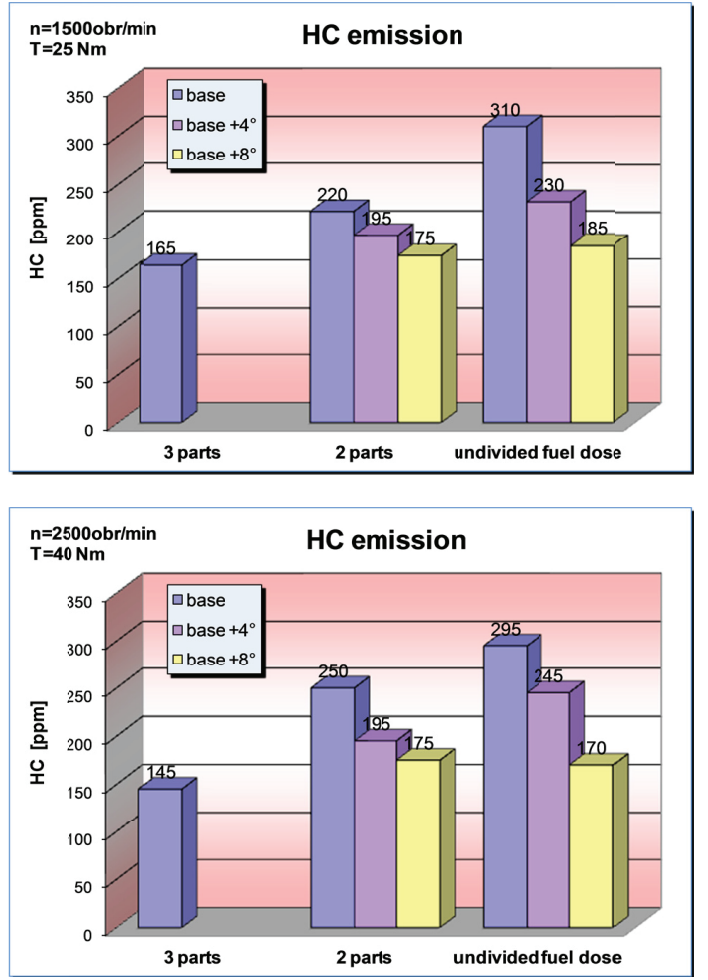

Fig. 7. HC content in the exhaust gas as function of fuel dose division and injection advance angle changes: $n=1500 \mathrm{rpm}$ and $T=25 \mathrm{Nm}$ (top), and $n=$ $2500 \mathrm{rpm}$ and $\mathrm{T}=40 \mathrm{Nm}$ (down)

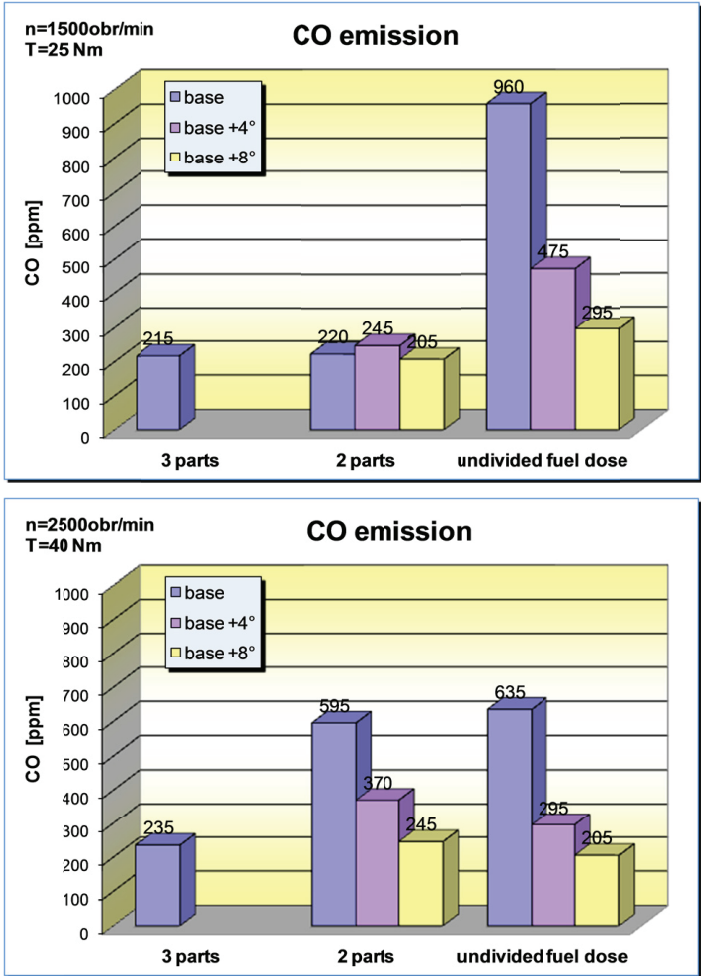

Fig. 8. CO content in the exhaust gas as function of fuel dose division and injection advance angle changes: $n=1500 \mathrm{rpm}$ and $T=25 \mathrm{Nm}$ (top), and $n=$ $2500 \mathrm{rpm}$ and $\mathrm{T}=40 \mathrm{Nm}$ (down)

Smoke opacity changes shown in Fig. 9 as a function of fuel dose division and IAA changes illustrate the unfavourable effect of fuel dose division on smoke opacity. This effect was clearly 
observed in both analysed engine operation cases. Dividing the fuel dose into two or three parts dramatically increases smoke opacity, compared to the undivided dose. Out of the two analysed cases, the dose division into two parts looks slightly more favourable. As for IAA control, for the undivided dose its effect is not clear, which can result from very small opacity values and limited sampling accuracy of the opacimeter. For fuel dose division into two parts, increasing IAA leads to the increase in smoke opacity by $20 \%$. The recorded values are lower by nearly $30 \%$ for the rotational speed $1500 \mathrm{rpm}$ and by $36 \%$ for $2500 \mathrm{rpm}$, as compared to the fuel dose divided into three parts. For the undivided dose, the smoke opacity is nearly three times as low for the rotational speed $1500 \mathrm{rpm}$ and twice as low for $2500 \mathrm{rpm}$ as that recorded for the fuel dose divided into three parts.
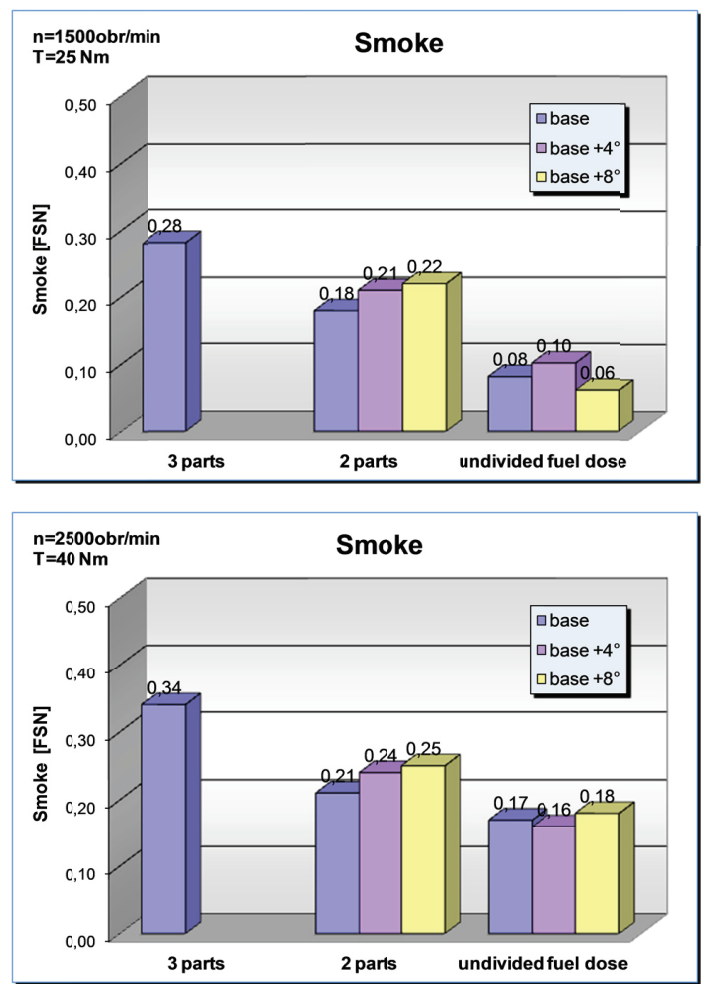

Fig. 9. Smoke opacity as function of fuel dose division and injection advance angle changes: $n=1500 \mathrm{rpm}$ and $T=25 \mathrm{Nm}$ (top), and $n=2500 \mathrm{rpm}$ and $\mathrm{T}=40 \mathrm{Nm}$ (down)

As the reference to the analysed changes of exhaust gas composition and smoke opacity as functions of fuel dose division and IAA changes, the bar graph of engine efficiency changes as a function of the above parameters is shown in Fig. 10.

The engine supplied with the fuel dose divided into three parts reveals slightly higher overall efficiency for the two analyses engine operation points than when it is supplied with the fuel dose divided into two parts or undivided. Even increasing IAA cannot compensate the efficiency drop caused by switching off the pilot and pre-injection phases.
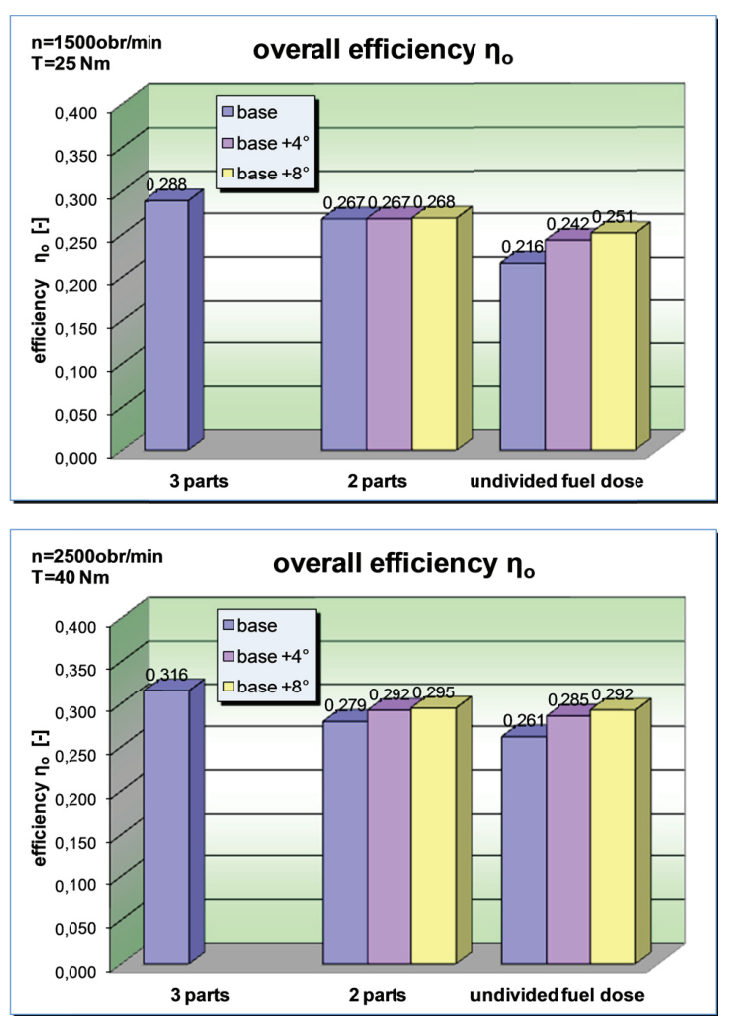

Fig. 10. Overall engine efficiency as function of fuel dose division and injection advance angle changes: $n=1500 \mathrm{rpm}$ and $T=25 \mathrm{Nm}$ (top), and $n=$ $2500 \mathrm{rpm}$ and $\mathrm{T}=40 \mathrm{Nm}$ (down)

\section{CONCLUSIONS}

The here reported research has revealed significant effect of fuel dose division on the exhaust gas composition and engine efficiency. The analysis of the obtained results enabled to state clearly that the number of parts into which the fuel dose is divided in one engine work cycle and the injection advance angles, both parameters composing the "volume-time" characteristic of the injection process, significantly affect the combustion process and, as a further consequence, the engine performance. They also affect the contents of harmful compounds and solid particles (manly soot) in the exhaust gas. The above statement is confirmed by conclusions resulting from the performed analysis:

- within the range of low rotational speeds and small engine loads, the engine revealed very high sensitivity to the introduced control changes, which was manifested itself in significant changes in exhaust gas composition,

- the $\mathrm{NO}_{\mathrm{x}}$ content in the exhaust gas clearly increased with the increase of the injection advance angle for the fuel dose divided into two parts, and even more for the undivided dose,

- on the other hand, increasing the injection advance angle resulted in the decrease of $\mathrm{CO}$ and $\mathrm{HC}$ contents in the exhaust gas. This enabled to reach the levels which were higher by slightly more than ten percent for higher IAA, or even lower in some cases (CO), as compared to the contents of these compounds when dividing the dose into 
three parts,

- bearing in mind good oxidising properties of the catalyser, manifested by negligible $\mathrm{CO}$ and $\mathrm{HC}$ contents in the exhaust gas behind it, the optimal injection advance angle for the fuel dose divided into two parts and the undivided dose (needed at high engine rotational speeds and loads) can be selected taking into account the level of NOx content in the exhaust gas and, to a lesser degree, the smoke opacity,

- fuel dose division significantly affects the level of smoke opacity in all examined engine operation states, in particular when the fuel dose is divided into three parts. This makes basic limitation for fuel dose division at higher engine rotational speeds and loads,

- within the low speed and load regime, dividing the fuel dose into three parts clearly and positively affects the contents of all analysed compounds of the exhaust gas, and improves the overall engine efficiency, at the same time keeping the smoke opacity at a permissible level. Therefore this mode of injection process control is sensible and recommendable within the engine low speed and load operation regime.

The publication has been produced as part of the research project no. 5178/B/T02/2011/40 financed from the resources of the National Science Centre.

\section{BIBLIOGRAPHY}

1. Kneba, K., Makowski, S., Engine fuel supply and control (in Polish), Wydawnictwa Komunikacji i Łączności, s. 308, Wydanie 1, Warszawa 2004.

2. Badami, M., Mallamo, F., Millo, F., Rossi E.E., Experimental investigation on the effect of multiple injection strategies on emissions, noise and brake specific fuel consumption of an automotive direct injection common-rail diesel engine, International Journal of Engine Research, Volume 4, Number 4, 1 December 2003.

3. Benajes, J., Molina, S. and Garcia, J. M., Influence of pre- and post-injection on the performance and pollutant emissions in a HD diesel engine, SAE Paper 2001-01-0526, 2001.

4. Rinolfi, R., Imarisio, R. and Buratti, R., The potential of a new common rail diesel fuel injection system for the next generation of DI diesel engines, In 16 Internationales Wiener Motorensymposium, Vol. 12, No. 239 (VDI-Verlag, Reihe).

5. Stelmasiak, Z., Knefel, T., Larisch, J., The influence of the time break of the fuel divided dose on the work parameters of the injector Common Rail system, Combustion Engines, No 2007-SC2, s.173-180, 2007.

6. Janiszewski, T., Mavrantzas, S., Electronic ignition systems for Diesel engines (in Polish), WKŁ, Warszawa 2001.
7. Pietras, D., Evaluation of the fuel dose distribution on the combustion process in a small diesel engine, Combustion engines No. 3/2011 (146), ISSN 0138-0346.

8. Pietras, D., Evaluation the sound pressure level of the small CI engine. Combustion Engines SC1 (Powertrain, Design, Ecology \& Diagnostics) 2009, str. 204-207.

9. Larisch, J., Knefel, T., Stelmasiak, Z., Pietrasina, W., A Development Control Unit For Common Rail Injection System, Paper registered under No. PTNSS P05-C158, PTNSS Congress 2005, Bielsko-Biała-Szczyrk 2005.

10. Stelmasiak, Z., Knefel, T., Larisch, J., Research programmer for Common Rail injection system, Pomiary, Automatyka, Kontrola 2010 Vol. 56 nr 3 . - s. 217-220.

11. Knefel, T., Comparative analysis of chosen injection time of multipartial fuel delivery, Technical Transactions 2012, z.9, ISSN 0011-4561, s. 115-129.

12. Knefel, T., Technical assessment of common rail injectors on the ground of overflow bench tests, Maintenance and Reliability 2012, Vol. 14, No. 1. - ISSN 1507-2711, s. 42-53.

13. Boulouchos, K., Stelber, H., Schubiger, R., Eberle, M., Lutz, T., Combustion System and Process Optimisation for Large Diesel Engines with Common Rail Fuel Injection, MTZ $5 / 2000$.

14. Broge, J.L., The diesel is coming, Automotive Engineering Int., January 2004.

\section{CONTACT WITH THE AUTHOR}

\author{
Dariusz Pietras \\ e-mail: pietras@ath.bielsko.pl
}

University of Bielsko-Biala

Department of Combustion Engines and Vehicles ul. Willowa 2, 43-300 Bielsko-Biała

Poland 